\title{
Pharmacological Management of Obesity in Patients with Type 2 Diabetes: An Update
}

\author{
Eun Ju Lee, Tae Nyun Kim* \\ Department of Internal Medicine, Cardiovascular and Metabolic Disease Center, Inje University, Busan, Korea
}

Type 2 diabetes is closely linked with obesity. Obesity is associated with risk of both development and progression of type 2 diabetes, as well as cardiovascular disease. Although lifestyle modifications aimed at prompting weight reduction are cornerstone therapies in managing type 2 diabetes, weight reduction remains challenging for overweight and obese patients with type 2 diabetes. A shift in the approach to weight management in patients with type 2 diabetes is clearly needed. Pharmacotherapy should be considered as a realistic treatment option for patients with type 2 diabetes who cannot lose weight with health behavior modification alone. This review is focused on current pharmacotherapies for obesity to support the glycemic and weight loss goals of obese people with type 2 diabetes.

Key words: Obesity, Type 2 diabetes, Anti-obesity drugs, SGLT2 inhibitors, GLP-1 receptor agonists

\section{Introduction}

Obesity is a major driver in the development of chronic metabolic disorders, such as type 2 diabetes and atherosclerosis, which also substantially increase the risk of cardiovascular disease. ${ }^{1}$ In addition, obesity is associated with multiple comorbidities including colon, breast, kidney and digestive tract cancers as well as nonalcoholic fatty liver disease, osteoarthritis, sleep apnea, and depression. ${ }^{2}$ Weight reduction is a key therapeutic goal in both the management of obesity and type 2 diabetes. ${ }^{3}$

The increase in the prevalence of type 2 diabetes is closely linked to the obesity epidemic. According to the Diabetes Fact Sheet in Korea 2013, half of subjects with diabetes are obese (BMI $\left.\geq 25 \mathrm{~kg} / \mathrm{m}^{2}\right){ }^{4}$ A recent report from the Korean Society for the Study of Obesity showed that prevalence of obesity in Korean children and adolescents aged 6 to 18 was about $10 \%$ in $2011 .^{5}$ The worrisome trend is that the age of onset of obesity and type 2 diabetes is progressively getting younger.

Weight reduction in patients with type 2 diabetes is associated with a reduction in blood pressure, total cholesterol, and triglycer- ides, as well as a reduction in markers of inflammation and endothelial dysfunction. A Look Action for Health in Diabetes (AHEAD) study showed that a modest weight loss of 5-10\% can improve fitness, glycemic control, and cardiovascular disease risk factors in individuals with type 2 diabetes. ${ }^{6}$ Although intensive lifestyle intervention (ILI) can delay progression from prediabetes to type 2 diabetes and may be beneficial in the treatment of type 2 diabetes $^{7,8}$, the reality is that long-term weight loss through ILI is still difficult to achieve for most patients. Furthermore, the primary goal in pharmacological therapy of type 2 diabetes remains improvement of glucose control, and weight gain is commonly associated with many conventional glucose-lowering agents taken to reach the target A1C levels., ${ }^{910}$ Therefore, for obese patients with type 2 diabetes who cannot lose weight with lifestyle modification, anti-obesity pharmacotherapy should be considered as an alternative option. In using anti-hyperglycemic agents, avoidance of pharmacologically induced weight gain should also considered as a clinically important goal. ${ }^{11}$

Given that weight management is essential for the health of overweight and obese patients with type 2 diabetes, this review will focus on the most clinically relevant information for pharmacotherapies
Corresponding author Tae Nyun Kim (iD http://orcid.org/0000-0001-6568-2469 Division of Endocrinology and Metabolism, Department of Internal Medicine, Inje University Haeundae Paik Hospital, 875 Haeun-daero, Haeundae-gu, Busan 48108, Korea Tel +82-51-797-0661, Fax +82-51-797-2070, E-mail kimtn031@gmail.com
Copyright (C) 2016 Korean Society for the Study of Obesity

(c) This is an Open Access article distributed under the terms of the Creative Commons Attribution Non-Commercial License (http://creativecommons.org/licenses/by-nc/4.0/) which permits unrestricted non-commercial use, distribution, and reproduction in any medium, provided the original work is properly cited. 
(newer anti-obesity drugs and anti-hyperglycemic agents with weight-loss potential) to support the glycemic and weight loss goals of obese people with type 2 diabetes. We will also provide the evidence to support their safety so that clinicians can prescribe these drugs with confidence.

\section{Anti-hyperglycemic agents with weight loss benefit}

weight reduction may bring desirable outcomes to obese or overweight people with type 2 diabetes due to its positive impact on glycemic control, insulin sensitivity, and comorbid health conditions. In addition, weight loss in obese patients with type 2 diabetes is associated with a reduction in blood pressure, triglycerides, inflammatory markers, and endothelial dysfunction. ${ }^{12}$ Current guidelines recommend weight loss treatment for all obese or overweight people with type 2 diabetes. ${ }^{13}$ However, many traditional glucose-lowering drugs commonly result in weight gain. In that regard, newer antihyperglycemic agents offer promise for combatting the dual burden of hyperglycemia and obesity simultaneously. They include glucagon-like peptide-1 receptor agonists (GLP-1 RAs) and sodium-glucose co-transporter 2 (SGLT2) inhibitors.

\section{GLP-1 receptor agonists}

GLP-1 RAs activate GLP-1 receptors ${ }^{14}$, causing a glucose-dependent increase in insulin with a decrease in glucagon secretion while increasing satiety and slowing gastric emptying. ${ }^{15,16}$ GLP-1 RAs exert diverse actions on multiple-target tissues and lead to a reduction in blood glucose and in body weight. ${ }^{17,18}$ GLP-1 RAs are injected subcutaneously twice daily, daily, or weekly depending on the formulation. There are currently four GLP-1 RAs available for use in Korea: exenatide (BYETTA), lixisenatide (LYXUMIA), liraglutide (VICTOZA), and dulaglutide (TRULICITY). When used as second- or thirdline medications, the GLP-1 RAs achieve $0.6 \%$ to $1.9 \%$ A1C lowering. ${ }^{19}$ GLP-1 RAs were associated with an average weight loss of 2.8 $\mathrm{kg}$ in a meta-analysis of 25 clinical trials. ${ }^{20}$ However, all GLP-1 RAs appear to be equally effective at reducing weight. Bolli et al demonstrated that significant weight loss with lixisenatide one-/two-step once daily after 24 weeks as compared to placebo (-2.6/-2.7 vs -1.6 kg, $P<0.001) .{ }^{21}$ A 26 -week head-to-head comparison of liraglutide (1.8 mg daily) and exenatide (10 $\mu$ g twice daily) showed that liraglutide and exenatide were associated with similar weight losses (liraglutide -3.24 [0.33] kg vs. exenatide -2.87 [0.33] kg, $P=0.2235) .{ }^{22}$ On the other hand, although both treatment were associated with progressive decreases in body weight, patients with type 2 diabetes taking liraglutide once daily lost more weight than did those taking exenatide once weekly (liraglutide once daily -3.57 [0.18] kg vs exenatide once weekly $-2.68[0.18] \mathrm{kg}, P=0.0005)$, irrespective of body mass index. ${ }^{23}$ In a network meta-analysis of 51 randomized control trials (RCT) involving GLP-1 RAs, exenatide $10 \mu \mathrm{g}$ twice daily reduced weight compared with exenatide $5 \mu \mathrm{g}$ twice daily [mean differences of -1.07 $\mathrm{kg}$ (95\% CI: -2.41, -0.02)], liraglutide $0.6 \mathrm{mg}$ once daily [-2.38 kg (95\% CI: -3.71, -1.06)], liraglutide $1.2 \mathrm{mg}$ daily [-1.62 kg (95\% CI: -2.79 , -0.43)], and placebo treatment [-1.92 kg (95\% CI: $-2.61,-1.24)] .^{24}$ In addition, reductions of weight treated with liraglutide $-1.8 \mathrm{mg}$ once daily reached statistical significance [-1.43 kg (95\% CI: -2.73, -0.15)] vs liraglutide $-1.2 \mathrm{mg}$ once daily. ${ }^{24}$ Although the precise mechanism associated the weight loss has not been elucidated, GLP-1 RAs cause weight loss in a dose-dependent manner, possibly through early satiety and delayed gastric emptying. ${ }^{25}$ The most common adverse effect noted in clinical trials with GLP-1 RAs was nausea, ranging from $11 \%$ to $44 \%$, with lower rates of nausea associated with the longer acting drugs. ${ }^{26}$ There have been reports of acute pancreatitis with the GLP-1 RAs, and these drugs are not recommended for use in patients with a history of pancreatitis. However, a meta-analysis of 60 clinical trials involving several GLP-1 RAs found no increased risk of pancreatitis, and large-scale and prospective studies will address questions surrounding a possible association. There has been concern that GLP-1 RAs may be associated with thyroid tumor and cancer. Medullary thyroid cancer has been observed in rodents treated with liraglutide. However, a recent meta-analysis found no increased risk of thyroid cancer with liraglutide or exenatide ${ }^{27}$, and a retrospective cohort study showed that exenatide use was not associated with an increased risk of benign thyroid neoplasm (Relative risk (RR) 0.7; CI 0.3-1.7), or pancreatic cancer (RR 0.8; CI 0.5-1.6). ${ }^{28}$

\section{Sodium-glucose cotransporter 2 inhibitors}

SGLT2 inhibitors are a newer class of diabetes drugs that inhibit the reabsorption of the glucose in the kidneys independent of insulin, thereby increasing glycosuria, and thus lowering blood glucose. 
Table 1. Summary of anti-hyperglycemic agents with weight loss benefit and newer anti-obesity agents

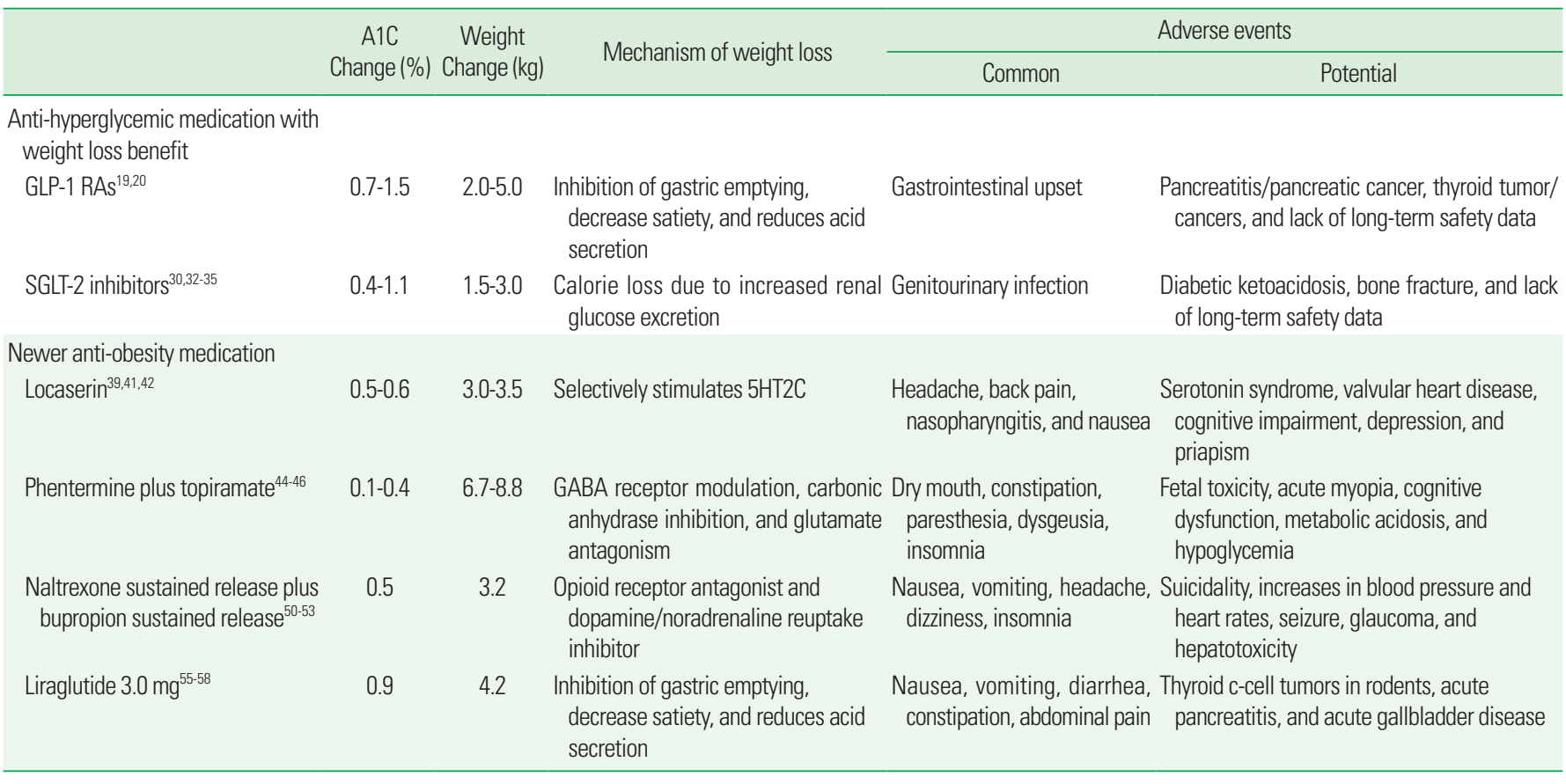

GLP-1 RAs, glucagon-like peptide-1 receptor agonists; SGLT2 inhibitors, sodium-glucose cotransporter 2 inhibitors; 5HT2C, 5-hydroxytryptamine 2C; GABA, gamma-aminobutyric acid.

The U.S. Food and Drug Administration (FDA) has approved three SGLT2 inhibitors, canagliflozin (Invokana, 2013), dapagliflozin (Forxiga, 2014), and empagliflozin (jardiance, 2014). Some other drugs in this class such as ipragliflozin (Suglat), tofogliflozin (Apleway, Deberza) and luseogliflozin (Lusefi) are approved in Japan. ${ }^{29}$ These drugs decreaseed both fasting and postprandial blood glucose levels, and resulted in an $\mathrm{A} 1 \mathrm{C}$ reduction between $0.5 \%$ and $1.0 \% .^{30} \mathrm{In}$ addition, they improved blood pressure and beta-cell function. ${ }^{30,31}$ Furthermore, SGLT-2 inhibitors on average resulted in a reduction in weight, as much as 1.5 to $3 \mathrm{~kg}$, possibly due to a loss of calories by reduction in glucose reabsorption. ${ }^{32,33}$ The weight loss appeared to be sustained for up to 102 weeks. ${ }^{14,33}$ Genital tract infections, predominately vulvovaginal candidiasis amongst women, have consistently been found to be more common with use of SGLT-2 inhibitors, whereas RCT data evaluating the risk of urinary tract infections are conflicting with some identifying no increase in risk and other reporting a small increase in risk. ${ }^{32-35}$ However, the number of hypoglycemic episodes experienced by patients treated with SGLT-2 inhibitors did not differ from placebo. Although not readily apparent in RCT data, post-marketing case reports of diabetic ketoacidosis following the use of SGLT-2 inhibitor persuaded the FDA to add this on the medication labeling. In addition, the FDA added a warning about a potential risk of bone fracture with the use of canagliflozin in patients with type 2 diabetes. Early studies with dapagliflozin raised concerns about a potential for increased incidence of bladder cancer. The U.S. FDA has requested post-marketing surveillance for potential risk of bladder cancer, and its use in patients with active or history of bladder cancer should be avoided. ${ }^{25}$ Further studies are required to evaluate these potential risks. On the other hand, a recent study of empagliflozin in patients with both cardiovascular disease and type 2 diabetes showed reduced rates of cardiovascular events and all-cause mortality when this medication was added to patients' standard diabetic care, including statins, antihypertensive medications, and additional diabetes medications including insulin and metformin. ${ }^{36}$ These effects of empagliflozin point strongly towards non-atherothrombotic mechanisms, probably hemodynamic effects. Further mechanistic studies will be needed to identify these mechanisms. In addition, further data are needed to understand if the reduction in cardiovascular outcomes with empagliflozin is a class effect. SGLT2 inhibitors may be best used in combination with other agents and can be used in combination with metformin, sulfonylurea, thiazolidinediones, dipeptidyl-peptidase 4 inhibitors, and basal insulin. 


\section{Newer anti-obesity agents}

Modest and sustained weight loss has been shown to improve glycemic control and to reduce the need for glucose-lowering medica-

tions in overweight or obese patients with type 2 diabetes. ${ }^{6,12}$ Not only intensive lifestyle interventions, but also alternative options, such as pharmacotherapy, need to be considered. The antiobesity medications can help patients to more consistently adhere to lowcalorie diets and to reinforce lifestyle changes including physical activity. Recently, four antiobesity medications for long-term weight management have been approved in U.S. They are lorcaserin (Belviq, 2012), phentermine plus topiramate (Qsymia, 2012), naltrexone plus bupropion (Contrave, 2014), and liraglutide $3.0 \mathrm{mg}$ (Saxenda, 2014).

\section{Lorcaserin}

Lorcaserin, a novel selective $5-\mathrm{HT}_{2 \mathrm{C}}$ receptor agonist, is approved for weight management in combination with lifestyle modification for obese adults, and overweight adults, and adults with $\geq 1$ weightrelated comorbid condition. ${ }^{37}$ The $5-\mathrm{HT}_{2 \mathrm{C}}$ receptor in the hypothalamus modulates food intake by activating the proopiomelanocortin system of neurons that induces hypophagia and regulates mechanisms related to satiety, ingestive behavior, glucose tolerance, and hepatic insulin sensitivity. ${ }^{38-40}$ The safety and effectiveness of lorcaserin in adult patients without diabetes was established based on two phase III clinical trials of similar design (BLOOM and BLOSSOM trial). ${ }^{41,42}$ These trials showed that lorcaserin $10 \mathrm{mg}$ twice daily, in combination with diet and exercise is associated with statistically significant weight loss (average weight loss of $5.8 \pm 0.2 \mathrm{~kg}$ with lorcaserin and $2.2 \pm 0.1 \mathrm{~kg}$ with placebo during 1 year, $P<0.001)$ and clinically relevant improvements in cardiometabolic parameters (lipid level, insulin resistance, inflammatory maker, and blood pressure). In a phase III study of subjects with type 2 diabetes (BLOOM-DM trial), lorcaserin treatment resulted in mean weight changes of $-4.5 \%$ (twice daily) and -5.0\% (once daily) compared with -1.5\% with placebo at week $52 .{ }^{39}$ Lorcaserin was associated with significant improvement in glycemic control in patients with type 2 diabetes: A1C decreased $-0.9 \%$ and $-1.0 \%$ from baseline with lorcaserin twice daily and once daily, respectively, vs $-0.4 \%$ with placebo $(P<0.001$ for each lorcaserin dose). The most common adverse events associated with lorcaserin treatment were headache, back pain, nasopharyngitis, and nausea $^{39,41,42}$ and there was no evidence of increased FDA-defined valvulopathy.

\section{Phentermine plus topiramate}

Phentermine was approved by the US FDA in 1959 for short-term obesity treatment and stimulates increased hypothalamic release of norepinephrine with no detectable effect on serotonin. ${ }^{43,44}$ Topiramate approved for the treatment of epilepsy in 1996 and the prevention of migraine in 2004, is a fructose monosaccharide derivative with sulphamate functionality. Although the precise mechanism associated the weight loss has not been elucidated, topiramate cause weight loss, possibly through increased energy expenditure, decreased energetic efficiency, and decreased caloric intake. ${ }^{44}$ Controlled-release phentermine/topiramate (PHEN/TPM CR) is an antiobesity medications combining immediate release phentermine and controlled-release topiramate given in a single daily morning dose. In a phase III trial (CONQUER trial) for overweight or obese adults with a body-mass index of $27-45 \mathrm{~kg} / \mathrm{m}^{2}$ and two or more comorbidities (hypertension, dyslipidaemia, diabetes or prediabetes, or abdominal obesity), patients with type 2 diabetes achieved weight reductions of $-6.8 \%$ with PHEN 7.5/TPM 46.0 and $-8.8 \%$ with PHEN 15.0/TPM 92.0 vs $-1.9 \%$ with placebo and had greater reductions in glycated haemoglobin with both doses of phentermine plus topiramate than with placebo. ${ }^{45}$ In the 108-week extension study (SEQUEL trial), weight loss was maintained for a second year and the progression to type 2 diabetes among participants without diabetes was lower in the PHEN/TPM-treated patients $(2.8 \%$ in the $7.5 / 46 \mathrm{mg}$ and $1.7 \%$ in the $15 / 92 \mathrm{mg}$ ) compared with those receiving the placebo (3.6\%). ${ }^{46}$ Paresthesia, nausea, dizziness, constipation, and dry mouth were the most commonly reported treatment-emergent adverse events. ${ }^{46}$ There were neuropsychiatric adverse events including depression, anxiety, insomnia, and disturbances in attention. PHEN/ TPM is contraindicated in pregnancy because of concerns about the increased risk of orofacial clefts in infants of topiramate. ${ }^{47}$

\section{Naltrexone sustained release plus bupropion sustained release}

Naltrexone is an opioid receptor antagonist approved for use in the management of alcohol and opioid dependence, whereas bupro- 
pion is a norepinephrine and dopamine reuptake inhibitor approved for use as an antidepressant and smoking cessation agent. ${ }^{48}$

The naltrexone/bupropion (NB) combination increases proopiomelanocortin (POMC) neuronal firing and increased POMC neuronal firing increases secretion of melanocortins such as a-melanocyte stimulating hormone, which is thought to mediate anorectic effects and regulate energy balance which may have anorectic effects. Also, NB combination therapy are believed to influence the mesolimbic dopaminergic reward system,which can modulate reward behaviors such as food intake. ${ }^{49}$ Three phase III trials of naltrexone SR plus bupropion SR (NB) in overweight or obese patients without diabetes demonstrated significant weight loss with an acceptable safety profile. In the COR-I and COR-II studies ${ }^{50,51}$, mean body weight changes were -6.1 and $-6.4 \%$ with NB vs. -1.3 and $-1.2 \%$ with placebo and were $-9.3 \%(\mathrm{NB})$ and $-5.1 \%$ (placebo) in the COR-BMOD study ${ }^{52}$, which included a more intensive, group-based lifestyle intervention. In phase III trials of NB for the treatment of overweight or obese patients with type 2 diabetes, $\mathrm{NB}$ combination therapy resulted in a $5.0 \%$ reduction in body weight, compared with a reduction of $1.8 \%$ with placebo and weight loss was maintained for the 56-week period, with no evidence of weight regain. ${ }^{53}$ This weight loss was associated with improvements in glycemic control (A1C: placebo-corrected difference $-0.5 \%$ ) and select cardiovascular risk factors (waist circumference, triglycerides, and HDL-C). The most frequently reported adverse event with NB was nausea which led to withdrawal in $10 \%$ of NB patients and constipation, headache, vomiting, dizziness, insomnia, dry mouth, and diarrhea were common adverse effects. ${ }^{54}$ The naltrexone-bupropion combination, although resulted in greater weight loss, can lead to elevations in blood pressure and pulse compared with placebo, but the clinical significance is unclear. Therefore, this drug requires blood pressure monitoring, and should not be used in patients with uncontrolled hypertension. Medications containing bupropion should not be administered to patients with a history of seizure disorders or those with anorexia or bulimia nervosa due to reduced seizure threshold.

\section{GLP-1R agonists (Liraglutide, $3.0 \mathrm{mg}$ )}

Liraglutide, a glucagon-like peptide-1 analogue with 97\% homology to human glucagon-like peptide-1 has been shown to have a potential benefit of weight management at a once-daily dose of $3.0 \mathrm{mg}$, injected subcutaneously. ${ }^{55}$ Liraglutide $(3.0 \mathrm{mg}$ ) was approved by the FDA in December 2014 for chronic weight management in addition to a reduced calorie diet and physical activity. Weight loss with liraglutide is mediated by reduced appetite and energy intake rather than by increased energy expenditure. ${ }^{56,57}$ In a 56 -week, doubleblind trial involving 3,731 patients who did not have type 2 diabetes, patients in the liraglutide group lost a mean of $8.4 \pm 7.3 \mathrm{~kg}$ of body weight, and those in the placebo group had lost a mean of $2.8 \pm 6.5$ $\mathrm{kg} .{ }^{55}$ Such as locaserin, phentermine/topiramate extended-release, naltrexone/bupropion, liraglutide treatment was associated with concurrent reductions in glycemic variables and multiple cardiometabolic variables (blood pressure, lipid levels, high sensitivity Creactive protein, plasminogen activator inhibitor-1, and adiponectin), as well as improvements in health-related quality of life. Among Patients with type 2 diabetes, liraglutide $(3.0 \mathrm{mg})$ daily, compared with placebo, resulted in weight loss over 56weeks: $6.0 \%(6.4 \mathrm{~kg})$ with liraglutide (3.0-mg dose), 4.7\% (5.0 kg) with liraglutide (1.8-mg dose), and $2.0 \%(2.2 \mathrm{~kg})$ with placebo. ${ }^{58}$ Similar to liraglutide $1.8 \mathrm{mg}$ treatment, the most frequently reported adverse events noted in clinical trials with liraglutide was gastrointenstinal events (nausea, diarrhea, constipation, and vomiting) and the incidence of gallbladder-related events was higher. A numerical imbalance was observed in the incidence of malignant and premalignant breast neoplasm but, the reason is unclear.

\section{Conclusion}

Type 2 diabetes is a serious disease that is associated with increased morbidity and premature mortality, mainly due to cardiovascular disease. Obesity is chronic disease that is associated with type 2 diabetes and cardiovascular disease. The escalating global epidemic of type 2 diabetes and cardiovascular disease is fueled by rising obesity rates. Weight loss is beneficial in overweight or obese people with type 2 diabetes to optimize glycemic and metabolic control and risk factors related to cardiovascular disease. Although health-behavior modifications aimed at prompting weight reduction are cornerstone therapies in managing type 2 diabetes, these effects (5-10\% weight loss and weight maintenance) are seldom sustained. A shift in the approach to weight management in patients with type 2 diabetes is clearly needed. Clinicians should preferentially use anti-hyperglycemic agents with weight benefit potential such as GLP-1 RAs, SGLT-2 
inhibitors and metformin. In addition, they should consider the weight loss effects of pharmacotherapies, such as locaserin, phentermine/topiramate extended-release, naltrexone/bupropion, and liraglutide, in the management of patients with type 2 diabetes. We hope this review will inspire practicing health care practitioners to translate the new advances in the pharmacotherapy of weight loss into treatment of overweight or obese patients with type 2 diabetes.

\section{Conflicts of Interest}

The authors have no conflicts of interest to declare.

\section{Acknowledgments}

This research was supported by Priority Research Centers Program through the National Research Foundation of Korea (NRF) funded by the Ministry of Education, Science and Technology (20100020224).

\section{References}

1. Van Gaal LF, Mertens IL, De Block CE. Mechanisms linking obesity with cardiovascular disease. Nature 2006;444:875-80.

2. Pender JR, Pories WJ. Epidemiology of obesity in the United States. Gastroenterol Clin North Am 2005;34:1-7.

3. Inzucchi SE, Bergenstal RM, Buse JB, Diamant M, Ferrannini E, Nauck M, et al. Management of hyperglycemia in type 2 diabetes, 2015: a patient-centered approach: update to a position statement of the American Diabetes Association and the European Association for the Study of Diabetes. Diabetes Care 2015;38:140-9.

4. Lee DH, Jung KY, Park KS, Kim KM, Moon JH, Lim S, et al. Characterization of patients with type 2 diabetes according to body mass index: Korea National Health and Nutrition Examination Survey from 2007 to 2011. Endocrinol Metab (Seoul) 2015; 30:514-21.

5. Ha KH, Kim DJ. Trends in the diabetes epidemic in Korea. Endocrinol Metab (Seoul) 2015;30:142-6.

6. Wing RR, Lang W, Wadden TA, Safford M, Knowler WC, Bertoni AG, et al. Benefits of modest weight loss in improving cardiovascular risk factors in overweight and obese individuals with type 2 diabetes. Diabetes Care 2011;34:1481-6.
7. Look AHEAD Research Group, Wing RR. Long-term effects of a lifestyle intervention on weight and cardiovascular risk factors in individuals with type 2 diabetes mellitus: four-year results of the Look AHEAD trial. Arch Intern Med 2010;170:1566-75.

8. Knowler WC, Barrett-Connor E, Fowler SE, Hamman RF, Lachin JM, Walker EA, et al. Reduction in the incidence of type 2 diabetes with lifestyle intervention or metformin. N Engl J Med 2002; 346:393-403.

9. UK Prospective Diabetes Study (UKPDS) Group. Intensive bloodglucose control with sulphonylureas or insulin compared with conventional treatment and risk of complications in patients with type 2 diabetes (UKPDS 33). Lancet 1998;352:837-53.

10. Fonseca V, McDuffie R, Calles J, Cohen RM, Feeney P, Feinglos M, et al. Determinants of weight gain in the action to control cardiovascular risk in diabetes trial. Diabetes Care 2013;36:2162-8.

11. Scheen AJ, Van Gaal LF. Combating the dual burden: therapeutic targeting of common pathways in obesity and type 2 diabetes. Lancet Diabetes Endocrinol 2014;2:911-22.

12. Mitri J, Hamdy O. Diabetes medications and body weight. Expert Opin Drug Saf 2009;8:573-84.

13. Jensen MD, Ryan DH, Apovian CM, Ard JD, Comuzzie AG, Donato KA, et al. $2013 \mathrm{AHA} / \mathrm{ACC} / \mathrm{TOS}$ guideline for the management of overweight and obesity in adults: a report of the American College of Cardiology/American Heart Association Task Force on Practice Guidelines and The Obesity Society. Circulation 2014;129(25 Suppl 2):S102-38.

14. Bolinder J, Ljunggren Ö, Johansson L, Wilding J, Langkilde AM, Sjöström CD, et al. Dapagliflozin maintains glycaemic control while reducing weight and body fat mass over 2 years in patients with type 2 diabetes mellitus inadequately controlled on metformin. Diabetes Obes Metab 2014;16:159-69.

15. Amori RE, Lau J, Pittas AG. Efficacy and safety of incretin therapy in type 2 diabetes: systematic review and meta-analysis. JAMA 2007;298:194-206.

16. Cernea S, Raz I. Therapy in the early stage: incretins. Diabetes Care 2011;34 Suppl 2:S264-71.

17. Esposito K, Mosca C, Brancario C, Chiodini P, Ceriello A, Giugliano D. GLP-1 receptor agonists and HBAlc target of $<7 \%$ in type 2 diabetes: meta-analysis of randomized controlled trials. Curr Med Res Opin 2011;27:1519-28.

18. Tatarkiewicz K, Sablan EJ, Polizzi CJ, Villescaz C, Parkes DG. 
Long-term metabolic benefits of exenatide in mice are mediated solely via the known glucagon-like peptide 1 receptor. Am J Physiol Regul Integr Comp Physiol 2014;306:R490-8.

19. Wright JJ, Tylee TS. Pharmacologic therapy of type 2 diabetes. Med Clin North Am 2016;100:647-63.

20. Vilsbøll T, Christensen M, Junker AE, Knop FK, Gluud LL. Effects of glucagon-like peptide-1 receptor agonists on weight loss: systematic review and meta-analyses of randomised controlled trials. BMJ 2012;344:d7771.

21. Bolli GB, Munteanu M, Dotsenko S, Niemoeller E, Boka G, Wu Y, et al. Efficacy and safety of lixisenatide once daily vs. placebo in people with Type 2 diabetes insufficiently controlled on metformin (GetGoal-F1). Diabet Med 2014;31:176-84.

22. Buse JB, Rosenstock J, Sesti G, Schmidt WE, Montanya E, Brett $\mathrm{JH}$, et al. Liraglutide once a day versus exenatide twice a day for type 2 diabetes: a 26-week randomised, parallel-group, multinational, open-label trial (LEAD-6). Lancet 2009;374:39-47.

23. Buse JB, Nauck M, Forst T, Sheu WH, Shenouda SK, Heilmann $\mathrm{CR}$, et al. Exenatide once weekly versus liraglutide once daily in patients with type 2 diabetes (DURATION-6): a randomised, open-label study. Lancet 2013;381:117-24.

24. Sun F, Chai S, Li L, Yu K, Yang Z, Wu S, et al. Effects of glucagonlike peptide-1 receptor agonists on weight loss in patients with type 2 diabetes: a systematic review and network meta-analysis. J Diabetes Res 2015;2015:157201.

25. Gurgle HE, White K, McAdam-Marx C. SGLT2 inhibitors or GLP-1 receptor agonists as second-line therapy in type 2 diabetes: patient selection and perspectives. Vasc Health Risk Manag 2016; 12:239-49.

26. Prasad-Reddy L, Isaacs D. A clinical review of GLP-1 receptor agonists: efficacy and safety in diabetes and beyond. Drugs Context 2015;4:212283.

27. Alves C, Batel-Marques F, Macedo AF. A meta-analysis of serious adverse events reported with exenatide and liraglutide: acute pancreatitis and cancer. Diabetes Res Clin Pract 2012;98:271-84.

28. Dore DD, Seeger JD, Chan KA. Incidence of health insurance claims for thyroid neoplasm and pancreatic malignancy in association with exenatide: signal refinement using active safety surveillance. Ther Adv Drug Saf 2012;3:157-64.

29. Madaan T, Akhtar M, Najmi AK. Sodium glucose CoTransporter 2 (SGLT2) inhibitors: Current status and future perspective. Eur J
Pharm Sci 2016;93:244-52.

30. Wilding JP. The role of the kidneys in glucose homeostasis in type 2 diabetes: clinical implications and therapeutic significance through sodium glucose co-transporter 2 inhibitors. Metabolism 2014;63:1228-37.

31. Foote C, Perkovic V, Neal B. Effects of SGLT2 inhibitors on cardiovascular outcomes. Diab Vasc Dis Res 2012;9:117-23.

32. Stenlöf K, Cefalu WT, Kim KA, Alba M, Usiskin K, Tong C, et al. Efficacy and safety of canagliflozin monotherapy in subjects with type 2 diabetes mellitus inadequately controlled with diet and exercise. Diabetes Obes Metab 2013;15:372-82.

33. Rosenstock J, Jelaska A, Frappin G, Salsali A, Kim G, Woerle HJ, et al. Improved glucose control with weight loss, lower insulin doses, and no increased hypoglycemia with empagliflozin added to titrated multiple daily injections of insulin in obese inadequately controlled type 2 diabetes. Diabetes Care 2014;37:1815-23.

34. Ferrannini E, Berk A, Hantel S, Pinnetti S, Hach T, Woerle HJ, et al. Long-term safety and efficacy of empagliflozin, sitagliptin, and metformin: an active-controlled, parallel-group, randomized, 78week open-label extension study in patients with type 2 diabetes. Diabetes Care 2013;36:4015-21.

35. Häring HU, Merker L, Seewaldt-Becker E, Weimer M, Meinicke T, Broedl UC, et al. Empagliflozin as add-on to metformin in patients with type 2 diabetes: a 24-week, randomized, double-blind, placebo-controlled trial. Diabetes Care 2014;37:1650-9.

36. Zinman B, Wanner C, Lachin JM, Fitchett D, Bluhmki E, Hantel S, et al. Empagliflozin, cardiovascular outcomes, and mortality in type 2 diabetes. N Engl J Med 2015;373:2117-28.

37. Rueda-Clausen CF, Padwal RS, Sharma AM. New pharmacological approaches for obesity management. Nat Rev Endocrinol 2013;9:467-78.

38. Lam DD, Przydzial MJ, Ridley SH, Yeo GS, Rochford JJ, O’Rahilly $\mathrm{S}$, et al. Serotonin 5-HT2C receptor agonist promotes hypophagia via downstream activation of melanocortin 4 receptors. Endocrinology 2008;149:1323-8.

39. O’Neil PM, Smith SR, Weissman NJ, Fidler MC, Sanchez M, Zhang J, et al. Randomized placebo-controlled clinical trial of lorcaserin for weight loss in type 2 diabetes mellitus: the BLOOMDM study. Obesity (Silver Spring) 2012;20:1426-36.

40. Zhou L, Sutton GM, Rochford JJ, Semple RK, Lam DD, Oksanen $\mathrm{LJ}$, et al. Serotonin $2 \mathrm{C}$ receptor agonists improve type 2 diabetes 
via melanocortin-4 receptor signaling pathways. Cell Metab 2007;6:398-405.

41. Smith SR, Weissman NJ, Anderson CM, Sanchez M, Chuang E, Stubbe S, et al. Multicenter, placebo-controlled trial of lorcaserin for weight management. N Engl J Med 2010;363:245-56.

42. Fidler MC, Sanchez M, Raether B, Weissman NJ, Smith SR, Shanahan WR, et al. A one-year randomized trial of lorcaserin for weight loss in obese and overweight adults: the BLOSSOM trial. J Clin Endocrinol Metab 2011;96:3067-77.

43. Rothman RB, Baumann MH. Appetite suppressants, cardiac valve disease and combination pharmacotherapy. Am J Ther 2009;16: 354-64.

44. Allison DB, Gadde KM, Garvey WT, Peterson CA, Schwiers ML, Najarian T, et al. Controlled-release phentermine/topiramate in severely obese adults: a randomized controlled trial (EQUIP). Obesity (Silver Spring) 2012;20:330-42.

45. Gadde KM, Allison DB, Ryan DH, Peterson CA, Troupin B, Schwiers ML, et al. Effects of low-dose, controlled-release, phentermine plus topiramate combination on weight and associated comorbidities in overweight and obese adults (CONQUER): a randomised, placebo-controlled, phase 3 trial. Lancet 2011;377: 1341-52.

46. Garvey WT, Ryan DH, Look M, Gadde KM, Allison DB, Peterson CA, et al. Two-year sustained weight loss and metabolic benefits with controlled-release phentermine/topiramate in obese and overweight adults (SEQUEL): a randomized, placebo-controlled, phase 3 extension study. Am J Clin Nutr 2012;95:297-308.

47. Colman E, Golden J, Roberts M, Egan A, Weaver J, Rosebraugh C. The FDA's assessment of two drugs for chronic weight management. N Engl J Med 2012;367:1577-9.

48. Ornellas T, Chavez B. Naltrexone SR/Bupropion SR (Contrave): A new approach to weight loss in obese adults. P T 2011;36:255-62.

49. Morton GJ, Cummings DE, Baskin DG, Barsh GS, Schwartz MW. Central nervous system control of food intake and body weight. Nature 2006;443:289-95.

50. Greenway FL, Fujioka K, Plodkowski RA, Mudaliar S, Guttadau- ria M, Erickson J, et al. Effect of naltrexone plus bupropion on weight loss in overweight and obese adults (COR-I): a multicentre, randomised, double-blind, placebo-controlled, phase 3 trial. Lancet 2010;376:595-605.

51. Apovian CM, Aronne L, Rubino D, Still C, Wyatt H, Burns C, et al. A randomized, phase 3 trial of naltrexone SR/bupropion SR on weight and obesity-related risk factors (COR-II). Obesity (Silver Spring) 2013;21:935-43.

52. Wadden TA, Foreyt JP, Foster GD, Hill JO, Klein S, O'Neil PM, et al. Weight loss with naltrexone SR/bupropion SR combination therapy as an adjunct to behavior modification: the COR-BMOD trial. Obesity (Silver Spring) 2011;19:110-20.

53. Hollander P, Gupta AK, Plodkowski R, Greenway F, Bays H, Burns C, et al. Effects of naltrexone sustained-release/bupropion sustained-release combination therapy on body weight and glycemic parameters in overweight and obese patients with type 2 diabetes. Diabetes Care 2013;36:4022-9.

54. Yanovski SZ, Yanovski JA. Naltrexone extended-release plus bupropion extended-release for treatment of obesity. JAMA 2015; 313:1213-4.

55. Pi-Sunyer X, Astrup A, Fujioka K, Greenway F, Halpern A, Krempf M, et al. A randomized, controlled trial of $3.0 \mathrm{mg}$ of liraglutide in weight management. N Engl J Med 2015;373:11-22.

56. Wadden TA, Hollander P, Klein S, Niswender K, Woo V, Hale $\mathrm{PM}$, et al. Weight maintenance and additional weight loss with liraglutide after low-calorie-diet-induced weight loss: the SCALE Maintenance randomized study. Int J Obes (Lond) 2013;37:144351.

57. van Can J, Sloth B, Jensen CB, Flint A, Blaak EE, Saris WH. Effects of the once-daily GLP-1 analog liraglutide on gastric emptying, glycemic parameters, appetite and energy metabolism in obese, non-diabetic adults. Int J Obes (Lond) 2014;38:784-93.

58. Davies MJ, Bergenstal R, Bode B, Kushner RF, Lewin A, Skjøth TV, et al. Efficacy of liraglutide for weight loss among patients with type 2 diabetes: The SCALE diabetes randomized clinical trial. JAMA 2015;314:687-99. 